\title{
A PROTEÇÃO DO SER HUMANO NO CONTRATO DE TRABALHO: PRIVACIDADE, INTIMIDADE E PROTEÇÃO DE DADOS
}

\section{Otávio Bruno da Silva Ferreira ${ }^{1}$}

\begin{abstract}
RESUMO
O avanço tecnológico aumenta a transmissão de informações pessoais e acentua os riscos de violação dos direitos de personalidade. Este estudo procura responder a seguinte indagação: qual a proteção jurídica do trabalhador quanto aos seus dados pessoais tratados pelo empregador? O objetivo é investigar o nível de proteção de dados do trabalhador no cenário brasileiro. Para tanto, busca-se analisar a relação entre proteção de dados, privacidade e intimidade, a regulação da proteção de dados e a sua incidência aos contratos de trabalho. Metodologicamente, o estudo é de abordagem qualitativa e, quanto aos objetivos, exploratório, tendo como procedimento o levantamento bibliográfico.
\end{abstract}

PALAVRAS-CHAVE: Contrato de Trabalho. Intimidade. Privacidade. Proteção de dados. Proteção constitucional.

\section{THE PROTECTION OF THE HUMAN BEING IN THE LABOR CONTRACT: PRIVACY, INTIMACY AND DATA PROTECTION}

\section{ABSTRACT}

Technological advancement increases the transmission of personal information and accentuates the risks of violating personality rights. This study seeks to answer the following question: what is the employee's legal protection regarding his personal data processed by the employer? The objective is to investigate the data protection level of the worker in the Brazilian scenario. To this end, we seek to analyze the relationship between data protection, privacy and intimacy, the regulation of data protection and its impact on employment contracts. Methodologically, the study has a qualitative approach and, in terms of objectives, exploratory, using the bibliographic survey as a procedure.

KEYWORDS: Employment Contract. Intimacy. Privacy. Data protection. Constitutional protection.

\section{INTRODUÇÃO}

O avanço tecnológico tem provocado mudanças significativas no tecido social, alterando a dinâmica e relação entre tempo e espaço.

No contexto do tratamento e utilização de dados pessoais, captados em qualidade e

\footnotetext{
${ }^{1}$ Doutorando em Direito pela Universidade Federal do Pará. Mestre em Direito, Políticas Públicas e Desenvolvimento Regional pelo Centro Universitário do Estado do Pará - CESUPA. Professor da Graduação no Centro Universitário FIBRA. Professor convidado do Programa de Pós-Graduação Lato Sensu do Centro Universitário FIBRA e do Centro Universitário do Estado do Pará - CESUPA. Juiz do Trabalho do Tribunal Regional do Trabalho da 8a Região.
} 
quantidade exponencial, os cruzamentos de informações e a formação de perfis podem acarretar violação aos direitos e garantias fundamentos, diretamente relacionados ao aspecto da dignidade da pessoa humana. Aparentemente desconectados e isolados, o seu tratamento, por meio de tecnologias, permite oferecer um perfil pessoal e obter conhecimento sobre gostos, hábitos, interesses, etc. (LÓPEZ BALAGUER; RAMOS MORAGUES, 2020, p. 506).

Nesse cenário, a informação desponta como bem de valor para o desenvolvimento das relações, superando obstáculos físicos e ocupando um espaço de centralidade na reorganização e nas formas de reprodução social.

A troca de informações e dados pessoais, considerados como direitos de personalidade e que decorrem do princípio geral da dignidade da pessoa humana, que podem ser utilizados para fins contrários ao Direito e à moral, como forma de perseguição política ou opressão econômica, por exemplo (BUCHAIN, 2019, p. 209), em tempo consideravelmente exíguo, é característica da atualidade, pautada pela era da informação.

Ao lado das vantagens advindas com a utilização dos avanços tecnológicos, há, por outro lado, problemas decorrentes da mesma origem, haja vista que o aumento da transmissão de informação, com a existência de múltiplas ferramentas, aumenta os riscos de obtenção de informações sem o consentimento do titular de dados e de sua utilização indevida, com comprometimento dos direitos da personalidade, dentre os quais a privacidade. Tal quadro exige a necessidade de uma tutela efetiva para essa nova dimensão, especialmente o direito à proteção de dados.

Com a aquisição de um número exponencial de informações e dados, é indispensável a existência de controle e a verificação da adequação de seu uso. Isto porque a dinâmica, como conhecemos ou como fora conhecida por nossos antecipados, construída a partir da separação entre o público e o privado, entre a família e o trabalho, bem como os direitos individuais, especialmente relacionados à intimidade e à privacidade do indivíduo, está sendo colocada em debate diante do novo panorama, com a possibilidade de poder sobre o indivíduo.

A necessidade de um equilíbrio entre as inovações tecnológicas e os direitos humanos deve ocupar espaço de debate e ser regulado com a adoção de atos de precaução e a definição das regras indispensáveis para neutralizar eventuais excessos e danos.

Como assinala Bruno (2020), a privacidade, não sendo uma condição natural, está sujeita a variações, mas estas não seguem um princípio evolutivo que levaria a sua extinção, mas são (e foram sempre) o efeito de embates sociais, políticos, econômicos. Daí porque 
destaca que a história da privacidade é uma história política do cotidiano, onde a micro e a macro-política não cessam de se misturar.

O mundo do trabalho não está fora da conflituosidade gerada pela utilização desenfreada de dados pessoais. López Balaguer e Ramos Moragues (2020, p. 509) afirmam que, nas relações de trabalho, a troca de informações é uma constante, e que o desenvolvimento das ferramentas tecnológicas se projetam sobre a privacidade dos trabalhadores em três perspectivas: i) permitem às empresas um maior acesso, tanto qualitativa quanto quantitativamente, a informações pessoais dos trabalhadores; ii) eliminação das fronteiras entre a vida laboral e a vida privada e iii) o exercício de controle mais incisivo do cumprimento das obrigações laborais em decorrência dos novos sistemas tecnológicos.

No contrato de trabalho, o parâmetro para intromissão do empregador aos dados do trabalhador é resolvido pela necessidade do empreendimento. Assim, o tratamento dos dados, especialmente os dados sensíveis, somente é autorizado quando o trabalhador estiver encarregado da execução de tarefas específicas que façam exigir o conhecimento daquelas informações.

Considerando esse cenário, o regramento sobre a proteção de dados surge com o intuito de proteger os direitos fundamentais de privacidade, de liberdade, dentre outros, a partir de uma tutela efetiva das informações, que consiga protegê-las do acesso de terceiros e que obriguem o seu tratamento adequado por aqueles que a possuem.

O direito à proteção de dados como direito autônomo decorre da observação de novas situações que ensejam proteção legal, seja por simples tratamento de dados pessoais, seja pela possibilidade de adoção de atitudes discriminatórias, como perfil racial, exames préadmissionais, lista de trabalhadores que já tenham feito reclamação em face do exempregador, dentre outros.

Por isso, o presente estudo tem o objetivo de responder a seguinte indagação: qual a proteção jurídica do trabalhador quanto aos seus dados pessoais tratados pelo empregador?

Para tanto, aponta-se como objetivo geral investigar o nível de proteção de dados do ser humano trabalhador no cenário brasileiro. São objetivos específicos do presente estudo: i) analisar a relação entre a proteção de dados, a privacidade e a intimidade; ii) identificar o marco legal de proteção de dados no Brasil e iii) investigar a respectiva incidência nos contratos de trabalho.

A partir do problema de pesquisa, as análises deste estudo, metodologicamente, são de 
abordagem qualitativa e, quanto aos objetivos, exploratórias. Como procedimentos, tem-se o levantamento bibliográfico, especialmente artigos doutrinários sobre a temática.

Além da introdução e das considerações finais, o texto está estruturado em mais três seções. Na primeira delas, far-se-á uma abordagem sobre o direito à proteção de dados, à privacidade e à intimidade, com apontamento dos traços que os distinguem. Na segunda, discorrer-se-á sobre o marco regulatório da proteção de dados no Brasil. Por fim, na última seção, analisar-se-á a incidência das normas sobre os contratos de trabalho.

Entende-se que o presente estudo apresenta-se como contribuição para a discussão sobre os rumos hermenêuticos, com o apontamento da necessidade de proteger, de forma efetiva, os titulares do direito que a normativa assegura proteção.

\section{DA DISTINÇÃO ENTRE O DIREITO À PROTEÇÃO DE DADOS, À PRIVACIDADE E À INTIMIDADE}

Para a compreensão do tema a ser tratado é fundamental ter como premissa que o direito à intimidade e o direito à proteção de dados apresentam substantividade que os distingue, inexistindo coincidência absoluta entre eles, embora, por vezes, sejam tratados como sinônimos. Assim, a violação de um não representa, por si só, a violação do outro.

Em linhas gerais, os dados pessoais são aqueles que servem para identificar uma pessoa e que, geralmente, estão relacionados à sua privacidade e que, por isso, encontram-se vinculados com a sua intimidade. Por outro lado, o conceito de intimidade é mais restrito, não abarcando todos os dados considerados pessoais de uma pessoa. Por essa razão, fala-se que a intimidade protege a esfera mais reservada das pessoas enquanto que a privacidade protege as variáveis da personalidade que, isoladamente consideradas, podem carecer de significação intrínseca, mas que, analisadas conjuntamente, projetam um retrato da personalidade do indivíduo que ele tem direito a manter reservado (MERCADER UGUINA, 2019, p. 23).

Por outro lado, a substantividade do direito à proteção de dados é reconhecida a partir do seu desprendimento de outros direitos de personalidade, tendo a ser visto de forma autônoma, com tratamento e conteúdo diferenciado, sendo necessário, portanto, uma tutela que considere essa particularidade.

A despeito de ambos os direitos objetivarem a proteção da vida privada da pessoa, o direito à intimidade estende a sua garantia à intimidade em sua dimensão constitucionalmente 
protegida, ou seja, sobre os dados íntimos da pessoa, enquanto que o direito à proteção de dados abarca a proteção aos dados que sejam relevantes ou tenham incidência no exercício de qualquer direitos da pessoa, sejam ou não direitos previstos no texto constitucional e sejam ou não relativo à sua honra, ideologia, intimidade ou qualquer outro bem. Assim, este último direito protege os dados pessoais em face do conhecimento ou emprego por terceiros, independente de estar ou não previsto em algum texto constitucional.

Interessa anotar que a distinção entre os direitos citados quanto à esfera de imposição a terceiros. Se, por um lado, o direito à intimidade confere o poder jurídico de impor a terceiros o dever de abstenção de toda e qualquer forma de intromissão na esfera íntima da pessoa e a proibição de fazer uso daquilo que é conhecido, o direito à proteção de dados representa um poder de disposição e de controle sobre os dados pessoais e faculta à pessoa decidir sobre quais dados pode ceder a terceiros, quais dados o terceiro pode coletar e garante ao titular dos dados a ciência sobre quem possui acesso ou guarda de seus dados pessoais e para qual motivo ou finalidade, assegurado o direito à oposição de seu uso.

A garantia de proteção ao direito de personalidade visa preservar o desenvolvimento do indivíduo, protegendo-o em face de violações contra sua identidade intelectual, física e moral. Por certo, a vida privada, consistente naquilo que é particular ao indivíduo, faz com que a privacidade figure como gênero do qual a intimidade atua como espécie (FINKELSTEIN; FINKELSTEIN, 2019, p. 284).

Por isso, pode-se dizer que o direito à privacidade serve à proteção do próprio direito da personalidade. Sarlet (2020, p. 188) enfatiza que, a despeito da citada relação, o conteúdo de um direito fundamental à proteção de dados pessoais, embora fortemente articulado com o princípio da dignidade da pessoa humana e de outros direitos fundamentais, em especial o direito ao livre desenvolvimento da personalidade e alguns direitos especiais de personalidade, como é o caso, entre outros, do direito à privacidade e do assim chamado direito à autodeterminação informativa, não se confunde com o do objeto da proteção de tais direitos.

Em sentido próximo, Pinto (2018, p. 642) discorre que o fundamento constitucional direto mais próximo de um direito fundamental à proteção de dados talvez seja mesmo o direito ao livre desenvolvimento da personalidade, radicado diretamente no princípio da dignidade da pessoa humana e no direito geral de liberdade, o qual também assume a condição de uma cláusula geral de proteção de todas as dimensões da personalidade humana, que, de acordo com tradição jurídica já consolidada no direito constitucional estrangeiro e no 
direito internacional (universal e regional) dos direitos humanos, inclui o (mas não se limita ao!) direito à livre disposição sobre os dados pessoais, o assim designado direito à livre autodeterminação informativa.

A histórica da privacidade sofreu um profundo impacto com a evolução da tecnologia, que permitiu tornar a vida cotidiana em palco do qual, por vezes, os expectadores são indetermináveis. Nesse cenário, assistiu-se a invasão da vida íntima por meio de monitoramentos facilitados pela tecnologia, que mostrou quão frágil era a tutela até então existente.

Finkelstein e Finkelstein (2019, p. 287) enfatizam que os dados coletados neste monitoramento são permanentes e, portanto, investigáveis por qualquer pessoa que tenha interesse em ter acesso a essas informações, com o aumento do que pode ser investigável.

Interessante observar que a definiação de privacidade como o direito de ser deixado só não está atualizado com a sociedade da informação. Atualmente, a garantia de privacidade abarca dimensões relativas à coleta e tratamento de dados pessoais, exigindo do Direito o disciplinamento necessário para atender as novas necessidades, especialmente os riscos decorrente do uso indevido das informações e dados captados por meio da inteligência artificial e do armazenamento de dados.

Neste ambiente, o reconhecimento de um direito fundamental à proteção dos dados pessoais "confere um novo e atual sentido à proteção da pessoa humana e da dignidade, da autonomia e das esferas de liberdade que lhes são inerentes" (MOLINARO, 2019, p. 183).

Por outro lado, para a compreensão do direito autônomo à proteção de dados pessoais, é necessário o diálogo com outros direitos, especialmente o direito à privacidade e o direito à autodeterminação informativa a fim de assimilar as distinções entre eles.

Sarlet (2020, p. 189) identifica o direito à autodeterminação informativa como um direito fundamental que consiste na prerrogativa de cada indivíduo de decidir, em princípio e substancialmente, sobre a divulgação e utilização de seus dados pessoais, que, por certo, não assegura a cada cidadão um controle absoluto sobre os seus dados, visto que, dada a inserção e responsabilidade comunitária e social do ser humano, este deve tolerar eventuais limitações do direito quando em prol do interesse geral.

Acrescenta ainda que a relação do direito à autodeterminação informativa com o princípio da dignidade da pessoa humana, portanto, é, em certo sentido, dúplice, pois se manifesta, tanto pela sua vinculação com a noção de autonomia, quanto com a do livre 
desenvolvimento da personalidade e de direitos especiais de personalidade conexos, de tal sorte que a proteção dos dados pessoais envolve também a salvaguarda da possibilidade concreta de tal desenvolvimento, para o qual a garantia de uma esfera privada e íntima é indispensável (SARLET, 2020, p. 190).

A despeito da confluência e da zona limítrofe que gera a distinção entre os direitos, não há uma sobreposição entre eles, seja entre a autodeterminação informativa e a proteção de dados, seja entre a privacidade e os outros direitos de personalidade. A justificativa é que o direito à autodeterminação informativa apresenta uma dupla dimensão, individual e coletiva, no sentido de que garantida constitucionalmente não é apenas (embora possa ser, como direito subjetivo individual, o mais importante) a possibilidade de cada um decidir sobre acesso, uso e difusão dos seus dados pessoais, mas também - e aqui a dimensão metaindividual (coletiva) - se trata de destacar que a autodeterminação informativa constitui precondição para uma ordem comunicacional livre e democrática, distanciando-se, nessa medida, de uma concepção de privacidade individualista e mesmo isolacionista à feição de um direito a estar só (right to be alone) (HORNUNG; SCHNABEL, 2009, p. 85).

Por isso, há sentido na afirmativa de Ruaro (2010, p. 189) para quem a proteção de dados pessoais e, da mesma forma, a autodeterminação informativa, vai além da privacidade e de sua proteção, ao menos no sentido tradicional do termo, caracterizado por uma lógica de "recolhimento" e "exposição". Isto significa que o objeto abrangido pela proteção de dados é mais amplo, abarcando todos os dados que dizem respeito a determinada pessoa natural, sendo irrelevante à qual esfera da vida pessoal se referem, seja íntima, privada, familiar ou social, sendo descabida qualquer tentativa de delimitação temática (BIONI, 2019, p. 95).

Por isso, conclui-se que o direito à proteção de dados é distinto, autônomo e mais abrangente que o direito à privacidade, vinculado diretamente à proteção da personalidade humana.

Ainda sobre aquele direito, Sarlet (2018, p. 288) observa que ele também, assim como ocorre como os direitos fundamentais em geral, possui uma dimensão dupla. Em sua dimensão subjetiva, se apresenta como um conjunto heterogêneo de posições subjetivas de natureza defensiva (negativa). Por outro lado, na sua dimensão objetiva, assume a condição de direito a prestações, cujo objeto consiste em uma atuação do Estado mediante a disponibilização de prestações de natureza fática ou normativa.

O direito à proteção de dados pessoais, na sua dimensão de direito subjetivo, apresenta 
uma variedade de posições relacionadas a outros direitos fundamentais.

Interessa destacar que o direito fundamental à proteção dos dados apresenta efeitos variados e relevantes, de conteúdo normativo, tanto na dimensão subjetiva quanto na objetiva. Sobre a primeira dimensão, o primeiro aspecto é o chamado efeito eficácia irradiante dos direitos fundamentais, no sentido de que esses, na sua condição de direito objetivo, fornecem impulsos e diretrizes para a aplicação e interpretação do direito infraconstitucional, o que, além disso, aponta para a necessidade de uma interpretação conforme aos direitos fundamentais, que, ademais, pode ser considerada - ainda que com restrições - como modalidade semelhante à difundida técnica hermenêutica da interpretação conforme à Constituição (SARLET, 2020, p. 198). Ao lado dele, identifica-se a constitucionalização do direito, incluindo o direito privado, produzindo a eficácia em relação a terceiros, conhecida como eficácia horizontal. Por fim, a terceira relevância é a colocação de um dever geral de efetivação atribuído ao Estado, competindo-lhe proteger os direitos fundamentais contra os poderes públicos e contra agressões particulares, na esfera repressiva e, especialmente, na preventiva.

Na dimensão objetiva, os direitos fundamentais representam parâmetros para a criação e a constituição de organizações (ou instituições) estatais e para o procedimento, funcionando como dependentes da organização e do procedimento, mas, simultaneamente, também atuando sobre o direito procedimental e sobre as estruturas organizacionais.

Além disso, entende-se que, mesmo dentro da atuação privada, não há como permitir uma ação livre dos direitos fundamentais, especialmente no tocante à proteção de dados, mormente quando o consentimento do titular não é dado de forma substancialmente livre, haja vista a imensa quantidade de contratos de adesão no mundo atual, a exigir rigoroso controle das restrições a direitos fundamentais nas relações privadas.

No mesmo sentido, Sarlet (2018. p. 414) discorre que os atores devem, no âmbito e limites de suas respectivas funções, competências e atribuições, aplicar e concretizar o direito à proteção de dados, assegurando-lhe a sua máxima eficácia e efetividade concreta, tanto na condição de direito subjetivo negativo (não intervenção arbitrária no seu âmbito de proteção), quanto, por força de sua dimensão objetiva, levando a sério os respectivos deveres de proteção e o critério da proibição de proteção insuficiente.

Fixadas as premissas iniciais distintivas do direito à proteção de dados e do direito à intimidade e o direito à intimidade, faz-se oportuno o exame proteção legal do primeiro no 
cenário brasileiro.

\section{DO REGIME JURÍDICO DE PROTEÇÃO DE DADOS NO BRASIL}

O regime jurídico de proteção de dados não é algo pronto e acabado. Ao contrário, os dilemas e obstáculos enfrentados desde o seu despertar demonstram a necessidade da exata compreensão e, especialmente, da extensão daquele direito fundamental autônomo.

Dentro de um panorama marcado pela coleta e cruzamento de dados a partir da utilização de tecnologias, como dito acima, a sociedade foi profundamente impactada, necessitando de novos direcionamentos para tratar de um novo direito: o direito à proteção dos dados.

Nesse cenário, no Brasil, foi aprovada a Lei $n^{\circ}$ 13.708/2018 (BRASIL, 2018), doravante denominada LGPD. Para fins de compreensão, apresentar-se-ão os principais elementos e os sujeitos que compõem o quadro de proteção de dados.

A LGPD (BRASIL, 2018) define dado pessoal como "informação relacionada a pessoa natural identificada ou identificável" (art. $\left.5^{\circ}, \mathrm{I}\right)$.

López Balaguer e Ramos Moragues (2020, p. 506) traçam que os dados amparados são todos aqueles que identifiquem ou permitam identificar a pessoa, servir para a confecção de seu perfil ideológico, racial, sexual, econômico ou de qualquer outra índole, ou que sirvam para qualquer outra utilidade que em determinadas circunstâncias constitua uma ameaça para o indivíduo.

Na visão de Cordeiro (2020, p. 107), a definição pode ser decomposta em quatro elementos distintivos e autonomizáveis: i) qualquer informação; ii) relativa a; iii) pessoa singular; e iv) identificada ou identificável.

Do primeiro elemento, destaca que toda informação é relevante, para efeitos de aplicação do Direito à Proteção de Dados, não se limitando a informação relativa à privacidade, abrangendo todos os aspectos relacionados à pessoa, quer familiares ou sociais, públicos ou privados, físicos ou mentais, independente do formato em que a informação foi recolhida e do suporte em que se encontra armazenada (CORDEIRO, 2020, p. 107).

No mesmo sentido, advertem Tepedino e Teffé (2019, p. 294), para quem, segundo a disposição legal, não existe dado pessoal insignificante, tendo sido adotado um conceito amplo de dado pessoal: informação relacionada a pessoa natural identifica ou identificável. 
Do segundo elemento, destaca que para ser pessoal a informação tem que ser relativa a uma pessoa, com exclusão de realidades jurídicas não subjetiváveis, de objetos, salvo quando conjugada com informação de uma pessoa e também quando seja possível identificar o titular do dado dentro de uma coletividade (CORDEIRO, 2020, p. 107).

Nas palavras de Doneda (2011, p. 93) é necessário para a caracterização de dado pessoal a existência de vínculo com a pessoa que faça revelar um aspecto objetivo de seu titular, referindo-se a características ou ações desta pessoa, que podem ser atribuídas a ela em conformidade com a lei, como no caso do nome civil ou do domicílio, ou então que são informações provenientes de seus atos, como os dados referentes ao seu consumo, informações referentes às suas manifestações, como sobre opiniões que manifesta e tantas outras.

Como pessoa singular, entende que a aplicação é restrita às pessoas singulares, independente de sua nacionalidade ou local de residência, afastando as pessoas coletivas e as realidades jurídicas não subjetiváveis, como as coisas e os animais (CORDEIRO, 2020, p. 107).

Por fim, da locução identificada ou identificável, identifica-se que identificada é quando a informação é suficiente para tanto, de forma inequívoca. Por outro lado, entende-se como identificável quando a informação é relativa a pessoa determinável, sempre quando haja uma probabilidade razoável de o responsável pelo tratamento ou de terceiros conseguirem identificar, por meio da conjugação de informação adicional à que já detêm ou não, a identidade do titular dos dados, ou seja, que torne a identificação possível, à luz de um juízo de razoabilidade.

Além disso, a LGPD (BRASIL, 2018) conceitua por "dado pessoal sensível” aquele sobre "dado pessoal sobre origem racial ou étnica, convicção religiosa, opinião política, filiação a sindicato ou a organização de caráter religioso, filosófico ou político, dado referente à saúde ou à vida sexual, dado genético ou biométrico, quando vinculado a uma pessoa natural" (art. 50, II).

Por fim, a LGPD (BRASIL, 2018) considera não identificável, ou "anonimizado", os dados relativos "a titular que não possa ser identificado, considerando a utilização de meios técnicos razoáveis e disponíveis na ocasião de seu tratamento" (art. $5^{\circ}$, III).

Outro conceito importante para a compreensão da temática é o de tratamento. Segundo a LGPD (BRASIL, 2018), o tratamento é "toda operação realizada com dados pessoais, como 
as que se referem a coleta, produção, recepção, classificação, utilização, acesso, reprodução, transmissão, distribuição, processamento, arquivamento, armazenamento, eliminação, avaliação ou controle da informação, modificação, comunicação, transferência, difusão ou extração" (art. 5, X).

A LGPD (BRASIL, 2018) não define as operações, razão pela qual a compreensão de seu conteúdo deve ser feita a partir da interpretação de seu conceito usual no mundo jurídico. Por outro lado, a locução "com as que" permite dizer que a lista é meramente exemplificativa, permitindo que o conceito de tratamento seja bastante amplo. Diante disso, qualquer operação que colha dados pessoais constitui uma espécie de tratamento e portanto estará sujeita à disciplina da proteção de dados.

Por previsão legal, estão excluídos do regime de proteção de dados pessoais: a) tratamento de dados realizado por pessoa natural para fins exclusivamente particulares e não econômicos ou, b) realizados para fins exclusivamente jornalísticos, artísticos e acadêmicos. Já as atividades de segurança pública, defesa nacional, segurança do Estado ou investigação e repressão de infrações penais serão regidos por legislação específica, que deverá observar o princípio da necessidade e da proporcionalidade no tratamento dos dados (BRASIL, 2018).

Cordeiro (2020, p. 143) decompõe o exame do tratamento a partir da análise de três vertentes: i) uma operação ou um conjunto de operações; ii) efetuadas sobre dados pessoais; e iii) por meio automatizados ou não automatizados.

Segundo ele, a operação corresponde a um ato jurídico, corresponde ao ato humano com repercussão jurídica, com a exclusão daqueles casos resultantes de destruição de dados decorrentes de ação não humana. Além disso, apenas apresentam relevância as operações efetuadas sobre dados pessoais. Por fim, o tratamento pode ser realizado pelos meios automatizados, parcialmente automatizados ou não automatizados (CORDEIRO, 2020, p. 143).

Do normativo citado, identifica-se o objetivo de proteger o titular de dados. Por outro lado, há outras pessoas que intervêm no tratamento de dados, dentre os quais, destacam-se o controlador e operador (agentes de tratamento) e o encarregado.

Segundo a LGPD (BRASIL, 2018), o "titular" é a "pessoa natural a quem se referem os dados pessoais que são objeto de tratamento", ou seja, a pessoa física identificada ou identificável (art. $\left.5^{\circ}, \mathrm{V}\right)$.

Por certo, Ruaro (2020) acentua que o titular dispõe do direito à proteção de dados 
pessoais em dupla dimensão: i) tutela da personalidade contra os riscos que ameacem sua personalidade em face da coleta, processamento, utilização e circulação dos dados pessoais, e, ii) a atribuição ao titular do direito a garantia do poder de controlar o fluxo de seus dados na sociedade, envolvendo tanto um aspecto subjetivo (controle dos dados pelo titular) quando um aspecto objetivo (proteção contra os riscos causados pelo tratamento dos dados pessoais).

Ao titular dos dados estão assegurados, segundo a LGPD (BRASIL, 2018), os seguintes direitos: a obtenção do controlador, em relação aos dados do titular por ele tratados, a qualquer momento e mediante requisição a confirmação da existência de tratamento; o acesso aos dados; a correção de dados incompletos, inexatos ou desatualizados; a anonimização, bloqueio ou eliminação de dados desnecessários, excessivos ou tratados em desconformidade com o disposto nesta Lei; a portabilidade dos dados a outro fornecedor de serviço ou produto, mediante requisição expressa, de acordo com a regulamentação da autoridade nacional, observados os segredos comercial e industrial; a eliminação dos dados pessoais tratados com o consentimento do titular, exceto nas hipóteses previstas no art. 16 desta Lei; a informação das entidades públicas e privadas com as quais o controlador realizou uso compartilhado de dados; a informação sobre a possibilidade de não fornecer consentimento e sobre as consequências da negativa e a revogação do consentimento.

Por outro lado, de acordo com a LGPD (BRASIL, 2018), o controlador é a "pessoa natural ou jurídica, de direito público ou privado, a quem competem as decisões referentes ao tratamento de dados pessoais". Corresponde à pessoa que toma a iniciativa e controla os meios técnicos e humanos necessário à implementação do tratamento.

Interessa observar que, como regra geral, o controlador deverá, primeiramente, ser considerado como a sociedade e não a pessoa que age em seu nome. A pessoa física será considerada controladora quando agir em nome próprio.

Outra situação que merece cuidado é sobre a contratação, pelo controlador, de prestadores de serviços (denominados pela lei como operadores), os quais serão solidariamente responsáveis pelos danos causados quando descumprirem a LGPD (BRASIL, 2018) ou quando não tiverem seguido as instruções lícitas do "controlador" (nesses casos o “operador" se equipara ao "controlador").

Por fim, destaca-se que a situação de controlador pode decorrer de três situações: i) a designação do controlador resulta de uma competência expressamente prevista em lei; ii) na ausência de disposição legal designando, expressamente, a identidade do controlador, 
seguem-se as regras gerais do direito para determinar sua identidade, como, por exmplo, a responsabilidade do empregador pelos atos do empregado e iii) insuficientes os métodos anteriores, recorre-se ao exame das circunstâncias fáticas, por meio do exame dos termos dos contratos para enquadrar as relações entre seus partícipes na operação de tratamento, mas também o efetivo grau de controle exercido por um partícipe na operação.

Por outro lado, a LGPD (BRASIL, 2018) define o "operador" como a "pessoa natural ou jurídica, de direito público ou privado, que realiza o tratamento de dados pessoais em nome do controlador" (art. 5, VII). Assim, a qualificação de "operador" exige da pessoa em causa o preenchimento de duas condições fundamentais: i) que seja uma entidade jurídica distinta do "controlador" e, portanto, dotada de personalidade jurídica própria e ii) que aja "em nome do controlador".

Essa segunda noção guarda alguma similitude com o contrato de mandato e significa que o operador deverá rigorosamente respeitar a LGPD (BRASIL, 2018) e se limitar a obedecer às instruções lícitas do "controlador", sob pena de responsabilidade solidária (art. 42, $\left.\S 1^{\mathrm{o}}, \mathrm{I}\right)$.

\section{A PROTEÇÃO DE DADOS NO CONTRATO DE TRABALHO}

O contrato de trabalho é marcado por relações que perpassam pelos direitos da personalidade. Sousa e Gonçalves (2020, p. 120), asseveram que a execução desse contrato é um ambiente propício à gestão de um conjunto elevado de dados pessoais e com bastante impacto na esfera jurídica do trabalhador, pois a relação que decorre de um contrato de trabalho entre empregador e trabalhador é, também, uma relação entre o responsável pelo tratamento de dados e o respetivo titular de dados pessoais.

Como dito acima, a irradiação dos direitos fundamentais sobre as relações privadas compõe, em certa dose, uma limitação aos poderes das partes contratantes. Por um lado, se ao empregador assiste o poder diretivo sobre o seu empreendimento, tal poder encontra-se limitado pelos direitos fundamentais do empregado, impedindo, em um primeiro momento, a inclusão de cláusulas contratuais que sejam contrárias àqueles direitos e, por segundo, a observância, ao longo e após o pacto laboral, dos ditames necessários à preservação da dignidade do trabalhador, por meio de uma adequada ponderação valorativa do direito fundamental e das obrigações que podem ser possíveis sem que possa falar em violação. 
A situação é bastante delicada em decorrência da ausência de uma liberdade substancial para discutir as cláusulas contratuais na relação laboral. Em regra, trata-se de um contrato de adesão, no qual a vontade do empregado é bastante limitada quando comparada com o conteúdo regulamentar disposto a favor do empregador, responsável pela oferta do trabalho.

Neste ponto, interessa anotar que, quanto aos dados pessoais, ainda mais em se tratando do mundo digital, a exigência do consentimento do titular dos dados e usuário das tecnologias de informação (aplicativos de toda ordem, mídias sociais, compras pela internet etc.), embora cogente do ponto de vista constitucional e legal, esbarra de modo substancial ainda que diferenciada - nas limitações à autonomia privada (SARLET, 2020, p. 209). Assim, até o consentimento do trabalhador deve ser visto com cautela, considerando a sua situação de vulnerabilidade.

Por certo, a celebração de um contrato de trabalho não implica, pelo trabalhador, em renúncia de qualquer direito assegurado nos textos fundamentais. Da mesma forma, a despeito da organização empresarial e dos poderes que lhe são assegurados, o empregador não está desacoplado da sociedade e das regulações, não havendo espaço para falar que possam impor limitações aos direitos fundamentais dos seus empregados.

Assim, assegura-se um determinado nível de proteção ao trabalhador, impondo ao empregador a obrigação de tratamento de dados pessoais não só ao longo da relação de trabalho, mas também nas fases prévia e pós-contratual.

No tocante aos dados coletados durante a relação laboral, identifica-se que a colheita ocorrer antes mesmo da celebração formal do vínculo, por meio de dados disponíveis em redes sociais e por meio de perguntas feitas durante a entrevista que, por vezes, vão bem além daquilo que é necessário ao empregador ter acesso para a prestação de um serviço que poderá (ou não) num futuro ser-lhe fornecido.

Por outro lado, a legislação impõe uma obrigação direta ou indireta sobre o empregador de manter um conjunto de informação ou registo sobre os seus trabalhadores, cujo conteúdo é essencial para a manutenção do contrato de trabalho ou simplesmente para garantir uma tutela do controle do cumprimento das regras laborais por parte das autoridades de inspeção.

Ainda na fase de recrutamento, que é, em rigor, o primeiro momento em que o empregador atua na qualidade de responsável pelo tratamento de dados pessoais de um 
candidato/trabalhador, são colhidos dados para o registro de pessoal, considerando a obrigação do empregador em manter um registo atualizado em cada estabelecimento dos seus trabalhadores, com a indicação de nome, datas de nascimento e admissão, modalidade de contrato, categoria, promoções, retribuições, datas de início e termo das férias e faltas que impliquem perda da retribuição ou diminuição de dias de férias.

Durante o contrato, o empregador fará colheita de dados nas seguintes situações: i) Registro de tempos de trabalho, incluindo horas extras e intervalos; ii) Registro de trabalhadores incluídos em cada turno de trabalho; iii) Registro de avaliações de riscos inerentes à atividade do trabalhador noturno; iv) Registro de sanções disciplinares; v) Informação sobre a manutenção de título profissional que permita o exercício de uma determinada profissão para o qual o trabalhador foi contratado; vi) Informação sobre relação de dependentes, dentre outras.

Há ainda os registros que resultam de necessidades práticas decorrentes da execução do contrato de trabalho, como, por exmplo: i) Dados bancários do trabalhador, para garantir a eficácia do pagamento das prestações salariais, embora o pagamento da retribuição possa ser realizado em dinheiro, cheque ou transferência bancária, esta última geralmente é o meio de pagamento mais consensual; ii) A informação sobre dados fiscais do trabalhador (extensível ao agregado familiar) para efeitos de retenção na fonte em sede de Imposto de Renda, dentre outros.

Além dos dados coletas por obrigatoriedade legal, o empregador terá acesso a outros dados do empregado em decorrência da atividade desenvolvida. Neste campo, ingressam os dados decorrentes de imagens de câmeras de circuito interno, geolocalização do trabalhador quando estiver portando aparelho de geolocalização (GPS), acesso ao conteúdo de e-mail corporativo, dentre outros. A concentração de uma infinidade de dados tratados pelo empregador representa risco à privacidade e à intimidade do trabalhador, sem falar em possível violação do direito à proteção de dados pessoais, por meio de uma instrusão excessiva e não justificada de manutenção e manuseio dos citados dados.

Acrescenta-se ainda que, mesmo após o fim do contrato, persistirá a obrigatoriedade legal de manutenção de certo dados.

Sousa e Gonçalves (2020, p. 131) pontuam que, com a cessação do contrato de trabalho, não se extingue a obrigação do empregador de manter o tratamento de dados pessoais do seu trabalhador, não sendo-lhe garantido o direito de apagar os dados pessoais que 
detenha de um trabalhador à data da cessação do contrato. Asssim, o empregador estará autorizado a guardar determinados dados após o término do contrato que estejam relacionados aos seguintes fatores: i) Conservação para fins probatórios; (ii) Conservação para garantia do controle da legalidade por autoridade de inspeção do trabalho e; iii) Conservação para cumprimento de prazos legais.

A referida guarda está em consonância, não apenas com os princípios da licitude, da limitação da finalidade, da minimização, da exatidão, da limitação da conservação, da integridade e da confidencialidade e responsabilização, mas principalmente em decorrência do cumprimento de obrigações legais, da execução de contrato e do legítimo interesse.

Diante desse cenário, surgem questionamentos que gravitam sobre o destino dos dados coletados dos trabalhadores, o grau de compromisso daquele responsável pela colheita e/ou pelo controle dos dados, a garantia do empregado de que seus dados não serão divulgados ou conhecidos por terceiros, o que, ao fim, caminham juntos para a indagação que norteou o presente estudo: qual a proteção jurídica do trabalhador quanto aos seus dados pessoais tratados pelo empregador?

\section{CONCLUSÃO}

A proteção dos dados do trabalhador constitui direito fundamental e autônomo, daí originando deveres de conduta e de cuidado, especialmente o desenvolvimento de parâmetros efetivos de proteção.

De acordo com Finkelstein e Finkelstein (2019, p. 284), o desenvolvimento tecnológico não apresenta somente aspectos negativos. A evolução da tecnologia dos mecanismos de monitoramento proporciona uma queda no tempo e nas despesas envolvidas em buscas. Já para aquele que está sendo investigado, existe a consciência de saber que sua privacidade pode estar sendo invadida.

Com a evolução das tecnologias de monitoramento, de um lado, a pessoa que busca as informações o faz muito mais rapidamente e a baixo custo econômico e, de outro lado, a pessoa investigada tem menor possibilidade de aperceber-se disso, e assim não sofre o inconveniente referido acima, presenciamos nesse particular o surgimento de uma nova ética, mitigando conceitos pré-estabelecidos em troca de um bem maior, que é a manutenção da paz. 
A probabilidade e a gravidade do risco para os direitos e liberdades do titular dos dados devem ser determinadas por referência à natureza, ao âmbito, ao contexto e aos objetivos do tratamento. Assim, no âmbito da relação laboral, na qual o empregador realiza a coleta de uma número extenso de dados do trabalhador, assumindo a característica de controlador, exige-se a necessária proteção dos referidos dados.

Por assim dizer, as balizas normativas para a licitude do tratamento de dados pessoais no contexto de um contrato laboral informam a necessidade de observância de, pelo menos, um dos seguintes hipóteses: i) tratamento necessário para o cumprimento de uma obrigação jurídica a que o responsável pelo tratamento esteja sujeito; ii) tratamento necessário para a execução de um contrato no qual o titular dos dados é parte, ou; iii) tratamento necessário para efeito dos interesses legítimos prosseguidos pelo responsável pelo tratamento ou por terceiros.

Nota-se que o direito à proteção de dados do trabalhador impõe ao empregador uma série de deveres de cuidado, em observância ao princípio da segurança, devendo dotar o seu empreendimento de meios efetivos de controle, guarda, segurança e registro de dados, de acordo com as orientações produzidas pelas autoridades competentes.

Assim, como resposta ao problema de pesquisa, entende-se que o direito à proteção de dados guarda fundamento constitucional, relacionado à própria dignidade do trabalhador, por meio do exercício e zelo dos seus direitos de personalidade. Como direito autônomo e distinto dos direitos à privacidade e intimidade, o direito à proteção de dados abarca todo e qualquer dado do ser humano trabalhador, permitindo falar em nível alto de proteção legislativa.

Por fim, a presente resposta não está isenta de críticas e não pretende ser opinião inquestionável. Ao contrário, está ao lado dos estudos que visam fomentar o debate sobre a matéria sobre tema recente com amplo alcance jurídico-social.

\section{REFERÊNCIAS BIBLIOGRÁFICAS}

BIONI, Bruno Ricardo. Proteção de dados pessoais: a função e os limites do consentimento. Rio de Janeiro: Forense, 2019.

BRASIL. Lei n 13.709, de 14 de agosto de 2018. Lei Geral de Proteção de Dados. Brasília: DF, Presidência da República, 2018. Disponível em: http://www.planalto.gov.br/ccivil_03/_ato2015-2018/2018/Lei/L13709.htm Acesso em 07 dez. 2020. 
BRUNO, Fernanda. O fim da privacidade em disputa. Disponível em: http://revistapontocom.org.br/edicoes-anteriores-artigos/o-fim-da-privacidade-em-disputa. Acesso em: 06 dez. 2020.

BUCHAIN, Luiz Carlos. A Lei Geral de Proteção de Dados: noções gerais. Revista dos Tribunais. vol. 1010. Ano 108. p. 209-229. São Paulo: Ed. RT, dezembro 2019.

CORDEIRO, Antônio Barreto Menezes. Direito da Proteção de Dados à luz do RGPD e da Lei n. ${ }^{0}$ 58/2019. Coimbra: Almedina, 2020.

DONEDA, Danilo. A proteção dos dados pessoais como um direito fundamental. Espaço Jurídico, Joaçaba, v. 12, n. 2, jul.-dez. 2011.

FINKELSTEIN, Maria Eugênia; FINKELSTEIN, Cláudio. Privacidade e Lei Geral de Proteção de Dados Pessoais. Florianópolis: Revista de Direito Brasileira, v. 23, n. 9, p. 284301, mai./ago. 2019.

HORNUNG, Gerrit; SCHNABEL, Christoph. Data protection in Germany I: The populational census decision and the right to informational self-determination. Computer Law \& Security Report, v. 25, issue 1, 2009.

LÓPEZ BALAGUER, Mercedez; RAMOS MORAGUES, Francisco. Control empresarial del uso de dispositivos digitales en el ámbito laboral desde la perspectiva del derecho a la protección de datos y a la intimidad. Lex Social: Revista De Derechos Sociales, 2020, p. 506-540

MERCADER UGUINA, Jesús Rafael. Protección de datos y garantía de los derechos digitales en las relaciones laborales. Ed. Francis Lefebvre. Claves Prácticas, Madrid, 2019.

MOLINARO, Carlos Alberto; SARLET, Gabrielle Bezerra Sales. Questões tecnológicas, éticas e normativas da proteção de dados pessoais na área da saúde em um contexto de big data. Belo Horizonte: Direitos Fundamentais \& Justiça, ano 13, n. 41, p. 183-212, jul./dez. 2019.

PINTO, Paulo Mota. Direitos de personalidade e direitos fundamentais: estudos. Coimbra: Gestlegal, 2018.

RUARO, Regina Linden; RODRIGUEZ, Daniel Piñeiro. O direito à proteção de dados pessoais na sociedade de informação. Direito, Estado Sociedade, n. 36, jan./jun. 2010.

SARLET, Ingo Wolfgang. Proteção de Dados Pessoais como Direito Fundamental na Constituição Federal Brasileira de 1988: contributo para a construção de uma dogmática constitucionalmente adequada. Belo Horizonte: Direitos Fundamentais \& Justiça, ano 14, n. 42, jan./jun. 2020.

SARLET, Ingo Wolfgang. A eficácia dos direitos fundamentais: uma teoria geral dos direitos fundamentais na perspectiva constitucional. 13. ed. Porto Alegre: Livraria do Advogado, 2018. 
SOUSA, Duarte Abrunhosa; GONÇALVES, Rui Coimbra. Da necessidade de conservação de dados pessoais dos trabalhadores no período pós-contratual. Revista de Direito do Trabalho e Seguridade Social. vol. 212. ano 46. p. 119-145. São Paulo: Ed. RT, jul./ago./2020.

TEPEDINO, Gustavo; TEFFÉ, Chiara Spadaccini de. Consentimento e proteção de dados pessoais na LGPD. In: FRAZÃO, Ana; TEPEDINO, Gustavo; OLIVA, Milena Donato (Coord.). A Lei Geral de Proteção de Dados Pessoais e suas repercussões no direito brasileiro. São Paulo: Revista dos Tribunais, 2019. 